\title{
A DIMENSÃO EDUCATIVA DA ENFERMAGEM NO SEU PROCESSO DE TRABALHO
}

\section{ARTIGO ORIGINAL}

ORIGA, Valquiria Castro de Morais ${ }^{1}$

COSTA, Elenice Alves da ${ }^{2}$

ORIGA, Valquiria Castro de Morais. COSTA, Elenice Alves da. A dimensão educativa da enfermagem no seu processo de trabalho. Revista Científica Multidisciplinar Núcleo do Conhecimento. Ano 05, Ed. 06, Vol. 04, pp. 95-133. Junho de 2020. ISSN: 2448-0959, Link de acesso: https://www.nucleodoconhecimento.com.br/saude/dimensao-educativa

\section{RESUMO}

A enfermagem tem agregado ao longo de seu percurso, a dimensão voltada à educação. Ela é expressa em diferentes atividades: na formação de enfermeiros, no treinamento da equipe de enfermagem e no atendimento dos usuários dos serviços de saúde. Este trabalho tem base bibliográfica e tem como objetivo o processo de trabalho em uma perspectiva educativa. Porém, há uma grande distancia entre os projetos educativos e as necessidades da população. $\mathrm{O}$ enfermeiro assistencial tem como função, treinar, capacitar, educar a sua equipe de trabalho e usuários dos serviços de saúde; enquanto o enfermeiro licenciado é responsável pela formação de seus alunos (tanto no ensino técnico quanto no universitário), podendo exercer atribuições assistenciais. Este trabalho também proporciona uma reflexão sobre a

${ }^{1}$ Pós-graduação em Gestão em Saúde, Especialização em Formação de Docentes para o Ensino Técnico e Superior em Enfermagem, Pós-graduação em Enfermagem do Trabalho e Bacharel em Enfermagem.

${ }^{2}$ Mestrado em Filologia e Língua Portuguesa. Especialização em Psicopedagogia Clínica e Institucional. Graduação em Letras. 
formação em enfermagem considerando as diretrizes curriculares, bem como relação teórica e prática no processo ensino e aprendizagem. Diante do exposto, é necessária revisão das ações educativas, levando-se em conta o ensino da enfermagem, competência profissional, existência ou não de instrumentos de avaliação, e o processo de enfermagem na condução do enfermeiro no desenvolvimento das ações educativas em todas as práticas de saúde.

Palavras-chave: Educação, ensino, enfermagem, métodos e Instrumentos de Avaliação.

\section{INTRODUÇÃO}

A assistência de enfermagem se destaca no atendimento de urgência desde os seus primórdios, com Florence Nightingale na guerra da Criméia, bem como Ana Nery na guerra do Paraguai. Já nos EUA, o atendimento pré-hospitalar (APH) na década de 1940, enfermeiras militares eram chamadas de Flight Nurses, se dedicavam ao transporte dos feridos de guerra. Na década de 1960, estas foram incorporadas às equipes de APH civis.

Mas foi no ano de 1983 que a Associação Americana de Enfermagem estabeleceu os "Padrões da Prática de Enfermagem em Emergência". Isso levou a classificação dos enfermeiros de emergência em três níveis de competências, sendo eles: Nível 1requer um mínimo de competência para assistir ao paciente traumatizado; Nível 2requer uma formação específica em enfermagem de emergência e Nível 3- requer especialidade em área bem delimitada e atuação no âmbito pré e intra- hospitalar.

De acordo com a Resolução COFEN - №. 290/2004, que fixa as especialidades de Enfermagem, no seu artigo 1을 tem-se a listagem das especialidades de Enfermagem, dentre as quais se destacam: Enfermagem Aeroespacial; Atendimento Pré-Hospitalar; Emergência; Trauma-Ortopedia; Terapia Intensiva (COFEN, 2004).

O enfermeiro que adentra esse campo da emergência traz sobre si grandes responsabilidades e é necessário que tenha tanto a prática quanto a teoria abrangente 
dessa área. De modo algum se prestará um bom atendimento sem a teoria, e esta se liga à prática em todos os seus aspectos. Da mesma forma, para ter sucesso no que faz, não basta apenas ter em mãos tecnologia de ponta, mas é imprescindível o conhecimento para utilizar essa tecnologia. Esse enfermeiro também deve ter algumas características que são essenciais para se trabalhar nesse setor: precisão, agilidade, destreza, iniciativa, criatividade e autocontrole; a presença dessas características representa um diferencial para o profissional que as têm. É importante ainda salientar que ele deve focalizar sua atenção no vasto campo de atuação que tem diante de si, ao invés de buscar práticas que são inerentes ao seu papel; quando ele se dispõe a realizar práticas de outras profissões, na verdade, engana a si mesmo fazendo pelos outros um trabalho que the pertence e, consequentemente, deixando de exercer o que realmente é o seu papel.

Dentro desse quadro, uma assistência de enfermagem sistematizada é essencial, tornando-se vital para um serviço de qualidade, preciso e eficaz. Essa sistematização está preconizada na Resolução do COFEN №. 300/2005, que dispõe sobre atuação do profissional de Enfermagem no atendimento Pré-hospitalar e Inter-hospitalar. No artigo 42, lê-se: "O Enfermeiro deverá desenvolver a Sistematização da Assistência de Enfermagem como forma de registro e anotações pertinentes à profissão e aos respectivos profissionais de enfermagem" (COFEN, 2005).

A sistematização ocorre através do Processo de Enfermagem. Sobre este, processo de enfermagem um método sistemático de prestação de cuidados humanizados, tendo como objetivo a obtenção de resultados desejados de um modo rentável. Ainda sobre ele, tem uma série de passos (investigação, diagnóstico de enfermagem, planejamento, implementação e avaliação) que tem como meta a individualização do cuidado através de uma abordagem de solução de problemas.

O processo de enfermagem, ou processo de cuidar, é um instrumento metodológico que possibilita identificar, compreender, descrever, explicar e ou predizer como a clientela responde aos problemas de saúde ou aos processos vitais, e determinar que aspectos dessas respostas demandem uma intervenção profissional de enfermagem. 
Feitas estas considerações iniciais, o presente estudo discorreu sobre a elaboração e validação de instrumentos para avaliação do processo de ensino da enfermagem.

\section{REVISÃO DE LITERATURA}

\subsection{A FORMAÇÃO EM SAÚDE: UM OLHAR PARA A AÇÃO EDUCATIVA}

A formação em saúde vem se tornando tema obrigatório nos debates referentes à efetivação e operacionalização do Sistema Único de Saúde (SUS) no país. Grande parte desses debates tem como uma das questões principais o distanciamento entre a formação dos profissionais de saúde e a prática esperada nos serviços.

De fato, diversos autores concordam ao afirmar que o SUS não consegue ser efetivamente operacionalizado se não houver uma força de trabalho qualificada para efetivá-lo nos serviços. Seus princípios e suas diretrizes precisam ser compartilhados e exercitados pelos profissionais que atuam nos serviços para o atendimento das necessidades de saúde da população nos diferentes níveis do sistema (FEUERWERKER, 2002; OLIVEIRA, 2004; CECCIM; FEUERWERKER, 2004; RIGOLI; ROCHA; FOSTER, 2006).

As diretrizes políticas para os recursos humanos do SUS, expressas pela Norma Operacional Básica, NOB/ RH-SUS, também são enfáticas ao preconizar a formação dos profissionais de saúde pautada nos princípios e diretrizes do SUS, com a finalidade de operacionalizar o Sistema nos serviços de saúde (BRASIL, 2003).

Apesar dessa preocupação com a formação em saúde, as Instituições de Ensino Superior (IES) formadoras dos profissionais de saúde por muito tempo resistiram em formar seus alunos com base nos princípios e diretrizes do SUS. Na verdade, essa resistência refletia, e em parte e ainda reflete a preponderância do modelo curativo, especializado e individualizado, amplamente difundido nos serviços de saúde entre as décadas de 50 e 60 . Esse modelo, que também é fruto da tendência mundial mercadológica de entender a saúde como ausência de doença e a assistência como 
um processo curativo e individual, imputava às instituições formadoras à necessidade de formar um contingente cada vez maior de profissionais de saúde que pudessem atuar nas instituições de saúde com esse perfil.

A formação inicia em saúde tornou-se tema de debate crescente nas últimas décadas no âmbito das diretrizes políticas na área de educação, alcançando grande visibilidade com a promulgação, em 2001, das Diretrizes Curriculares Nacionais (DCNs) para os cursos da área de saúde.

As DNCs, entre outras características, reafirmam a necessidade e o dever das IES em formar profissionais de saúde voltados para as necessidades de saúde da população Brasileira.

A interface entre as áreas de educação e saúde no que se refere à preocupação com a formação também pode ser exemplificada na atual política de formação da força de trabalho para os serviços de saúde no Brasil, da Secretaria da Gestão do trabalho e da Educação na Saúde (SGTES) do Ministério da saúde, expressa em três projetos: o AprenderSUS, o VerSUS e o Pró-Saúde.

Em linhas gerais, o projeto AprenderSUS, iniciado em 2004, apresenta como objetivo principal orientar mudanças nas graduações em saúde, com a finalidade de

[...] transformações das práticas profissionais e da própria organização do trabalho e estruturar-se a partir da problematização do processo de trabalho e sua capacidade de dar acolhimento e cuidado às várias dimensões e necessidades em saúde das pessoas, dos coletivos e das populações (BRASIL, 2004, S/P).

O VerSUS, desenvolvido pela parceria SGTES, entidades estudantis dos cursos da área de saúde e secretarias municipais de saúde, tem como uma de suas propostas oferecer vivencias e estágios no SUS a estudantes de graduação, com o objetivo de "promover a integração dos futuros profissionais à realidade da organização dos serviços, levando em consideração os aspectos de gestão do sistema, as estratégias 
de atenção, o controle social e os processos de educação na saúde" (BRASIL, 2007, $\mathrm{s} / \mathrm{p})$.

Finalmente, o Pró-Saúde, lançado em 2005, objetiva a reorientação do processo de formação em saúde com vistas a formar profissionais que possam operacionalizar o SUS nos serviços de saúde e responder às necessidades de saúde da população. Propõe uma intervenção no processo formativo para que as IES possam desenvolver programas de educação para os cursos de saúde que desloquem a formação centrada na assistência individual e especializada para um ensino baseado nas necessidades sociais e nos princípios e diretrizes do SUS (BRASIL, 2005).

Observa-se o esforço por parte do Ministério da Saúde, em articulação com o Ministério da Educação e entidades representativas das profissões em saúde, dentre elas a de Enfermagem, para promover mudanças na formação em saúde que tenham como eixo de ensino o SUS. Entretanto, colocar o SUS, seus princípios e diretrizes, e a necessidade de saúde implicam aceitar o desafio de transformar o modelo tradicional de assistência à saúde.

Para Campos (2003), esse modelo, centrado na atenção individual especializado, está se esgotando não somente pelo seu alto custo, mas também pelo baixo impacto nas condições de vida e saúde da população. Para reverter esse quadro, o autor defende a chamada Reforma Sanitária, na qual os diferentes saberes já produzidos na área da saúde possam ser articulados, integrados e aprofundados, com vistas a desenvolver novas formas de produzir saúde. Para realizar tal mudança no modelo de atenção é importante, dentre outros aspectos, ampliarem as ações de promoção, prevenção à saúde e participação social.

Esse novo paradigma de saúde teria como elemento central os modelos de atenção voltados para o reconhecimento e participação ativa dos sujeitos sociais envolvidos na assistência à saúde, particularmente os usuários. Para isso, é necessário pensar modelos de atenção que reforcem a educação em saúde, mas uma educação em saúde na qual os serviços e os profissionais apoiem a participação dos sujeitos sociais no controle e no planejamento de saúde de sua comunidade. 
Com essa preocupação, o relatório da $11^{\text {a }}$ Conferencia Nacional de Saúde (CNS) preconiza que um dos deveres das políticas de Informação, Educação e Comunicação em Saúde (IECS), no SUS, é o "fortalecimento da cidadania e do Controle Social, visando a melhoria da qualidade e a humanização dos serviços e ações de saúde" (BRASIL, 2001, p. 173).

Em relação à formação do profissional de saúde para a ação educativa, o relatório da $12^{\text {a }}$ CNS, realizada em 2003, em seu sétimo eixo temático intitulado "Trabalho na Saúde", no item "Formação dos profissionais de saúde" é enfático ao defender a necessidade de:

Modificar o modelo de formação dos profissionais de saúde, hoje centrado na atenção à doença, reformulando o currículo dos cursos dos profissionais de saúde, considerando temas teóricos e práticos relacionados com a promoção, a vigilância e a atenção integral à saúde, o controle social e o caráter multiprofissional e interdisciplinar das práticas da saúde. Incluir conteúdos disciplinares em informação e comunicação social sobre a diversidade étnica, cultural e racial do povo Brasileiro, aspectos da subjetividade relacionados com a atenção e a educação em saúde, redução de danos, atenção básica e saúde da família, qualidade da atenção, direitos e deveres de cidadania, e organização e funcionamento do SUS (BRASIL, 2004, p. 127).

Em que pese a importância dedicada às ações educativas desenvolvidas pelos profissionais de saúde, vários autores denunciam que a maioria dos projetos educativos realizados nos serviços de saúde são ineficientes e desconsideram a inserção social da população. Destacam que a formação desses profissionais, não os preparam para o enfrentamento das necessidades de saúde da população e, portanto, para práticas educativas que valorizem a participação e o controle social (VASCONCELOS, 2001; VALLA, 2005). 


\subsection{A AÇÃO EDUCATIVA DO ENFERMEIRO: UM OLHAR SOBRE O PROCESSO DE TRABALHO ASSISTIR}

A Enfermagem, como profissão historicamente dedicada ao cuidado humano, também tem se dedicado ao longo de seu percurso a uma dimensão educativa. São várias as autoras que discutem essa dimensão educativa, considerando-a como elemento fundamental no trabalho do enfermeiro (MONTICELLI, 1994; DILLY; JESUS, 1995; MEYER, 1998; SAUPE, 2004).

De maneira sintética, pode-se dizer que essa dimensão educativa se expressa em diferentes atividades: no ensino de enfermagem, praticado em instituições de ensino; na educação permanente da equipe de enfermagem e nas ações educativas desenvolvidas durante a assistência de enfermagem a usuários dos serviços de saúde, podendo ser individuais ou grupais, no interior dos serviços e da comunidade.

Essas atividades, apesar de distintas, coexistem no cotidiano de trabalho da enfermeira, permeando suas ações. É assim que durante a gerência de uma unidade de internação hospitalar, por exemplo, o enfermeiro toma como função a educação permanente de sua equipe, propiciando informação e capacitação aos profissionais, a chamada educação em serviço. Com outra finalidade educacional, desta vez a educação formal, um enfermeiro licenciado, professor de uma instituição de ensino técnico, leciona aos seus alunos. Em outro cenário, um enfermeiro da atenção básica, durante sua assistência, seja esta uma consulta, visita domiciliar, participação em grupos comunitários, nas reuniões do conselho local de saúde ou mesmo em um procedimento técnico (vacina, curativo, coleta laboratorial, exame de Papanicolau, entre outros) estabelece uma relação educativa com os usuários dos serviços de saúde.

Os exemplos que não se encerram aqui descritos, servem apenas para ilustrar a presença desse componente educativo na ação da enfermagem, nos processos de trabalho administrar, ensinar ou assistir. 
Esta pesquisa toma como objetivo o processo de trabalho assistido em sua dimensão educativa, entendendo que toda a assistência de enfermagem tem um caráter educativo, mesmo que este não esteja explícito ou que não seja a prioridade, mas o principal objetivo do cuidado planejado.

Dilly e Jesus (1995) confirmam essa posição ao considerar o enfermeiro como peça fundamental nas ações educativas em saúde desenvolvidas com os usuários dos serviços. Saupe (2004) ao investigar as práticas educativas desenvolvidas por enfermeiros de comunidades rurais do Rio Grande do Sul, também concluiu que as práticas educativas permeiam todo o processo de trabalho assistencial de enfermagem. Monticelli (1994), ao estudar as ações educativas em enfermagem, constatou que estas não apenas estão presentes no cotidiano de trabalho assistencial do enfermeiro, mas constituem um instrumento de trabalho desse profissional.

Apesar da importância dada ao papel do enfermeiro no desenvolvimento de ações educativas e do fato de estarem fortemente presentes em sua prática assistencial, observa-se que ainda há um grande distanciamento entre os projetos educativos desenvolvidos pelos enfermeiros nos serviços de saúde e as necessidades da população.

As práticas em saúde têm se prestado a atender diferentes interesses que variam e disputam espaço ao longo do tempo. O mesmo ocorre com as práticas educativas realizadas pelo enfermeiro. Alguns estudos evidenciam que tais práticas ainda estão voltadas para o simples repasse de informações ou para a mudança de comportamentos, não valorizando a perspectiva da participação social (BUDÓ; SAUPE, 2004).

O estudo de Budó e Saupe (2004) também destaca que a formação inicial do enfermeiro não a prepara para a prática educativa mais participativa e dialógica, como a defendida pela Educação Popular em Saúde, pois faltam competências e habilidades para que o enfermeiro possa desempenhar seu papel educativo. 


\subsection{AS AÇÕES EDUCATIVAS NO ENSINO DE ENFERMAGEM: UM BREVE RESGATE HISTÓRICO}

A discussão sobre as práticas educativas em saúde na enfermagem remonta ao período de criação do Departamento Nacional de Saúde Pública (DNSP). É a partir dessa instituição que enfermeiras norte-americanas convidadas por Carlos Chagas se fixam no país para atuar no controle e prevenção das epidemias e para aqui desenvolver a Enfermagem profissional (SILVA, 1986).

Foi assim que em 1923, fundou-se a primeira Escola de Enfermeiras Profissionais do DNSP que, a partir de 1926, passou a ser chamar Escola de Enfermeiras Ana Néri, atualmente Escola de Enfermagem da Universidade Federal do Rio de Janeiro.

Com a direção de Ethel Parsons, enfermeira norte-americana, a Escola adotou o modelo de educação em Enfermagem preconizado nos Estados Unidos, fundamentado no Informe elaborado por Abraham Flexner, que defendia, entre outros aspectos, a formação baseada nas ciências básicas, restringindo a compreensão do processo saúde-doença à dimensão biológica. Esse modelo de educação estava alinhado com o discurso preventivo e higienista proposto pelo DNSP (ARANTES, 1999).

O objetivo da escola era formar enfermeiras de saúde pública e, portanto, o currículo estava direcionado para o conteúdo e atividades preventivas, com ênfase nas ações educativas em saúde (GERMANO, 1983; RIZZOTO, 1999; BUDÓ; SAUPE, 2004).

As práticas educativas realizadas pelas enfermeiras constituíam um instrumento para que o Estado contivesse as grandes epidemias e controlasse sua força produtiva, os trabalhadores e suas famílias. Nesse aspecto, merecem destaque as enfermeiras visitadoras, que ao adentrar as residências, tinham em mente mudar o comportamento das famílias em relação à saúde, para deter e conter as doenças.

Ainda que marcadas pelo padrão de ensino norte-americano, baseado no modelo flexeneriano e sob a lógica da mudança de comportamentos, as ações educativas 
realizadas pelas egressas da Escola produziram impactos positivos na saúde das populações atendidas, contribuindo para a diminuição das taxas de mortalidade por doenças epidêmicas e endêmicas (SAUPE, 1998).

Em 1949, o modelo curricular de ensino passou por uma mudança, determinada pela lei $n^{\circ} 75$ e pelo decreto $n^{\circ}=27.426$. A lei uniformizou o ensino de Enfermagem, enquanto o decreto estabeleceu o currículo para formação de enfermeiras.

De acordo com Germano (1983), não houve uma mudança expressiva entre o primeiro currículo, estabelecido em 1923 e o currículo de 1949. Ambos privilegiavam os conteúdos de cunho preventivo e com caráter higienista. Entretanto, a mesma autora adverte sobre o surgimento de uma nova tendência: a formação para a assistência hospitalar. A porcentagem de enfermeiras atuando em saúde pública caiu de $66 \%$, em 1943, para $17,2 \%$ no ano de 1950 , enquanto a porcentagem de enfermeiras trabalhando no campo hospitalar saltou de $9,5 \%$ para $49,4 \%$ no mesmo período (SAUPE, 1998; GERMANO, 1983).

Essa nova tendência refletia a aceleração da industrialização e a preocupação com a manutenção da força de trabalho operária. Assim, as medidas de saúde começam a enfatizar a restauração da saúde dos trabalhadores por meio da assistência médica individualizada. Criaram-se grandes complexos médico-hospitalares nos centros urbanos, aumentando a demanda por cursos de Enfermagem voltados para a formação hospitalar.

As ações educativas fortemente presentes no currículo e na prática assistencial de enfermagem até 1940, cederam espaço para a assistência individualizada, hospitalar e privada (OLIVEIRA, 2004).

Mesmo no ambiente hospitalar, as ações educativas realizadas pelas enfermeiras também tinham como principal objetivo o controle das enfermidades, a partir da mudança de comportamentos das pessoas.

$\mathrm{Na}$ década de 60, com um modelo econômico caracterizado pela concentração de renda e pela continuidade da privatização da assistência médica individualizada, o 
ensino de Enfermagem passou por nova reformulação por meio do parecer ํㅡ. 271 de 1962. Nesse novo currículo, a principal transformação foi referente à inclusão das especializações. O currículo apresentava uma formação básica ou mínima e uma formação específica, representada pelas especializações em Saúde Pública e Enfermagem Obstétrica (GERMANO,1983).

A formação básica, com duração de três anos, incluía disciplinas de Administração e excluía as relacionadas às Ciências Sociais e à Saúde Pública.

Segundo Oliveira, "o deslocamento do conteúdo vinculado à Saúde Pública para a especialização evidenciava a ênfase nas ações individuais e curativas, num processo de medicalização da assistência à saúde" (OLIVEIRA, 2004, p.11).

Para Saupe (1998), esse novo currículo alterou o caminho que a Enfermagem trilhava desde a época de trinta, passando de uma orientação focada na saúde da totalidade da população para uma focalização na assistência prestada ao individuo hospitalizado. A formação para o desenvolvimento de ações relacionadas à saúde em Saúde ficou restrita a formação de enfermeiros com especialização em Saúde Pública. Aqui se verifica um grave problema, pois as ações educativas foram entendidas como atividades relacionadas, exclusivamente, a saúde pública. As ações educativas desenvolvidas nos espaços hospitalares não foram levadas em consideração.

Com a imposição da ditadura militar em 1964, observou-se a redução dos recursos destinados às políticas sociais, redirecionados para a introdução de novas tecnologias e o desenvolvimento econômico. A assistência de saúde permaneceu médicacentrada e hospitalocêntrica e as ações educativas ainda voltadas para a mudança de comportamentos (GALLEGUILLOS; OLIVEIRA, 2001).

O currículo de 1962 perdurou até 1972, ocasião em que houve a instituição do novo currículo por meio do Parecer no. 163. A nova estrutura curricular apresentava algumas novidades, dentre as quais se destacavam: a organização do currículo em matérias, possibilitando seu desdobramento em disciplinas; a constituição de um núcleo mínimo obrigatório, que poderia ser incrementado de acordo com as 
necessidades regionais; a mudança das especializações para as habitações em Saúde Pública, Enfermagem Obstétrica e Enfermagem Médico- Cirúrgica e, finalmente, a inclusão da Licenciatura (SAUPE, 1998).

Em relação a formação pedagógica relacionada à Educação em Saúde, observa-se a inclusão da disciplina "Didática aplicada à Enfermagem". Essa disciplina, inserida no núcleo comum do currículo, tinha como propósito assumir "a discussão do papel do educador em saúde, que o enfermeiro exerce junto aos indivíduos, grupos, famílias, população, e no treinamento em serviço do pessoal de Enfermagem" (BAGNATO, 1994, p. 167).

À Licenciatura em Enfermagem coube a responsabilidade de formar enfermeiros para os cursos profissionalizantes de Enfermagem e pelo ensino de Ciências no primeiro e segundo graus.

Ressalta-se que a Licenciatura em Enfermagem havia sido proposta por alguns profissionais da área como um espaço para a formação pedagógica do enfermeiro em todas as suas dimensões, do ensino formal às ações de educação em saúde. Essa preocupação com a formação pedagógica do enfermeiro foi albergada pela Associação Brasileira de Enfermagem em 1991, na "proposta de Novo Currículo Mínimo para Curso Superior de Enfermagem: a formação do enfermeiro". Entre idéias sugeridas estavam à inclusão da Licenciatura como parte da formação comum da enfermeira (ASSOCIAÇÃO BRASILEIRA DE ENFERMAGEM,1991).

Entretanto, a proposta não foi reconhecida pelo Ministério da Educação e Cultura e o novo currículo de Enfermagem, aprovado em 1994, excluiu da modalidade bacharelado a disciplina "Didática aplicada em enfermagem". A formação pedagógica do enfermeiro foi entendida pelos legisladores do MEC como restrita à formação em Licenciatura. De acordo com Saupe (1998), o currículo mínimo de 1994 evidenciava uma grave distorção e desconhecimento do papel educativo da Enfermagem, visualizando-o como limitado ao ensino formal e ausente da prática assistencial. 
Atualmente, a formação inicial em Enfermagem é rígida pela Lei de Diretrizes e Bases (LDB), DE 1996. Nos aspectos referentes ao ensino superior, a LDB propõe, entre outras medidas, a superação dos currículos mínimos e a adoção de Diretrizes Curriculares Nacionais (DCNs) para cada curso de graduação. As DCNs apresentamse como uma nova orientação geral a ser seguida pelas escolas de ensino superior, contendo elementos indicadores e norteadores da formação neste nível de ensino.

Para aproximar o ensino da prática profissional, a enfermagem realizou diversos fóruns de debates com professores, alunos e profissionais da área, por meio dos Seminários Nacionais de Diretrizes e Bases para a Educação em Enfermagem (SENADEn), promovidos pela Associação Brasileira de Enfermagem (ABEN) (MORAES, 2003).

Como resultado desses fóruns de debates, a categoria elegeu o SUS como referência para formulação de propostas para os cursos de graduação e o processo saúdedoença e seus determinantes históricos, sociais, econômicos e políticos como elementos norteadores da formação em Enfermagem.

As DCNs, para o Curso de Graduação em Enfermagem, resultaram desse movimento de discussão realizado pela Enfermagem ao longo das duas últimas décadas. Homologadas por meio da resolução n‥ 3 de 2001, do Conselho Nacional de Educação (CNE) e da Câmera de Educação Superior (CES), AS DCNs preconizam a formação do enfermeiro generalista, critica e reflexiva, capaz de conhecer e intervir sobre os problemas de saúde mais prevalentes, além de atuar com senso de responsabilidade social e compromisso coma cidadania, como promotor da saúde integral do ser humano (BRASIL, 2001).

As DCNs também recomendam que a formação do profissional de Enfermagem seja orientada para o desenvolvimento de competências. No parecer 16/99 do CNE e na CES o termo competência designa a capacidade de mobilizar conhecimentos, informações e habilidades para aplicação em situações concretas do exercício profissional (KOBAYASHI; LEITE, 2004, p.224). 
Das competências gerais e específicas listadas nas Diretrizes Curriculares para o Ensino Superior em Enfermagem, observa-se uma que relaciona a assistência de Enfermagem às ações educativas em saúde, referindo que a enfermeira deve ser capaz de " planejar e implementar programas de educação e promoção à saúde, considerando a especificidades dos diferentes grupos sociais e dos distintos processos de vida, saúde, trabalho e adoecimento" (BRASIL, 2001).

No item "Conteúdos Curriculares", o documento também postula que o ensino de Enfermagem deve orientar-se para "uma formação e capacitação pedagógica independente da licenciatura em enfermagem" (BRASIL, 2001). Fica evidente a preocupação em preparar enfermeiros para práticas educativas.

Entretanto, o documento não especifica quais são os conhecimentos, habilidades e atitudes necessárias para desenvolver competências relacionadas à prática educativa na assistência de enfermagem. Além disso, não deixa claro qual é a noção de educação em saúde empregada, dando margens para diferentes interpretações.

Apesar disso, as Diretrizes preconizam que a formação de todas as profissões da área de saúde deve estar orientada pelos princípios e diretrizes do SUS, de modo a assegurar a integralidade da atenção, a qualidade e a humanização da assistência e o atendimento das necessidades de saúde (BRASIL, 2001).

Nesse sentido, é possível aceitar uma aproximação coma temática da educação em saúde, na perspectiva da Educação Popular em Saúde, considerando que as práticas em saúde e a formação dos profissionais devem estar alicerçadas pelos princípios e diretrizes do SUS. Entretanto, faz-se necessário construir competências que possam conduzir os enfermeiros ao desenvolvimento de ações educativas. Foi com esse grande desafio que se desenvolveu este trabalho.

Considerando que a atenção à saúde possui um caráter educativo e que este deve estar alicerçado em uma prática pedagógica dialógica que parta das necessidades de saúde dos sujeitos sociais e, portanto, de seus conhecimentos e representações sobre seus modos de viver e de andar a vida, este trabalho destaca a dimensão educativa 
do enfermeiro em seu processo de trabalho assistencial, entendendo que a assistência de enfermagem tem uma dimensão educativa.

Frente ao distanciamento constatado entre a formação em saúde e as necessidades de saúde da população atendida pelos serviços de saúde, faz-se necessário que os processos formativos na área de saúde promovam a formação de profissionais de saúde que possam acolher essas necessidades e, a partir delas, promover práticas pedagógicas dialogadas e participativas, diminuindo assim o abismo criado entre o "mundo" do trabalho. Essa proposta pedagógica é a base da Educação Popular em Saúde.

\subsection{COMPETÊNCIAS}

A competência constrói-se na prática, no dia a dia, em diferentes situações que possibilitam a interação de conhecimentos de diversas áreas, numa conjugação aleatória, repetindo- se desempenhos e assimilando-se novos dados, graças ao engajamento pessoal na ação e um forte desejo de sucesso. $O$ desejo de sucesso deve ser subentendido como compromisso com a situação aliado ao respeito pela pessoa atendida. A competência, em sua gênese, passa por raciocínios explícitos, decisões conscientes, inferências e hesitações, ensaios e erros. Esse funcionamento pode automatizar-se e gradativamente constituir-se em um esquema complexo que servirá de ancoradouro para novas competências.

A competência implica saber articular conhecimentos (orquestrar esquemas) e mobilizá-los para situações concretas. Esta situação oferece dados que o indivíduo necessita mobilizar para elaborar esquemas de percepção (diagnosticá-la), de avaliação (poder elaborar hipóteses) e ação. A habilidade de mobilizar conhecimentos é uma conquista do indivíduo perante situações semelhantes e não se processa de maneira automática. O modo como o indivíduo consegue realizar entrelaçamento, a teia dos diversos saberes (conhecimento, atitudes, habilidades) constitui a força propulsora para a ação profissional. 
A escola pode organizar situações para o exercício da mobilização (transferência) de conhecimentos (PERRENOUD, 2000). A proposta de elaboração para relatórios com sucessivas aproximações prevê esse aspecto da competência.

O aluno vivencia várias situações em que necessita empregar o relatório como recurso e resposta de seu aprendizado. Em cada relatório enfrenta novos desafios, tanto no tema quanto na complexidade dele. A competência em pesquisa é entendida como a competência para planejar, implementar e divulgar uma pesquisa. Ela envolve competências menores especificadas como: analisar artigo científico, elaborar projeto de pesquisa, desenvolver na prática um trabalho de pesquisa, elaborar artigo científico e aplicar o método científico em situações práticas.

A articulação de saberes supõe a realização de operações mentais desde as mais simples até as mais complexas e abstratas que compreendem análises, sínteses, analogias, associações, generalizações e inferências (ANDRÉ e PASSOS, 2001).

A formação de competência profissional na escola depende da criação de atividades que possibilitem o exercício da mobilização de diferentes esquemas.

Estas situações de aprendizagem teriam que ser repetidas, em diferentes contextos, por aproximações sucessivas e cada aproximação deveria ser avaliada e remetida ao aluno, apontando os acertos e as possibilidades para contornar as falhas que porventura existam.

Outro aspecto que, segundo Bunier (2003), vem sendo valorizado em atividades de ensino é o trabalho coletivo. Este, favorece o desenvolvimento de habilidades éticas e sociais; saber conviver, respeitar opiniões e valores diferentes que são exigências do mundo atual e das situações de trabalho.

O ensino pelo Currículo Integrado considera o trabalho em grupo como uma das principais estratégias de ensino-aprendizagem e o ensino por competência no qual o aluno enfrenta situações concretas em sua área se encaixa nessa proposta. 
$\mathrm{Na}$ UEL, Universidade Estadual de Londrina, o Currículo Integrado do Curso de Graduação em Enfermagem, estruturado em módulos que envolvem várias áreas de conhecimento, trabalho em pequenos e médios grupos, já oferece evidências sobre a veracidade dessa informação. Os alunos encontram facilidade em se organizar para a execução das atividades propostas, facilidade para expor suas idéias e na apresentação da produção do grupo (UEL, 1999).

Sintetizam- se as conceituações de autores e formula nosso próprio conceito e ressaltam alguns aspectos: as competências refletem conhecimentos mobilizados no momento da ação, os quais valem-se de esquemas internalizados em diferentes momentos da aprendizagem, construídos em situações práticas, resultantes da interação de conhecimentos de vários domínios do comportamento humano (cognitivo, técnico, ético e político), os quais exigem do indivíduo consciência sobre os limites impostos pelo contexto e compromisso em intervir nas situações que impedem ou dificultam o exercício da cidadania.

A competência para agir e transformar o mercado de trabalho é uma conquista de longo prazo, mas inerente à intencionalidade utópica do professor.

A competência pode ser inferida através de desempenhos que, para Ramos (2001) seriam as expressões concretas dos recursos que o indivíduo articula e mobiliza no enfrentamento de situações. O desempenho, por ser a expressão do saber do indivíduo em situação concreta e permite ao professor acompanhar o desenvolvimento do aluno até a meta de competências específicas que a vida profissional exige. O envolvimento do professor na aprendizagem do aluno possibilitaIhe retomadas de conteúdo teórico, treinamento em procedimentos e reflexão sobre atitudes e emoções no enfrentamento de situações concretas.

O desempenho é um recurso fundamental para acompanhar os avanços do aluno nas atividades planejadas para o ensino de Metodologia da Pesquisa, assim como, na conquista das competências esperadas para o graduando. 
Ramos (2001) realça que o desempenho pode ser observado e Perrenoud (1999) afirma que o desempenho observado seria um indicador mais ou menos confiável de uma competência.

A observação do desempenho favorece uma relação do professor com o aluno que pode ser autoritária ou comprometida. Autoritária quando aponta o certo e errado refletindo na atribuição de notas. Comprometida quando o professor é movido pelo desejo profundo, conforme salienta Luckesi (1998), de que o aluno aprende e supera as limitações do momento.

As situações de aprendizagem planejadas, no Curso de Enfermagem da UEL, são norteadas pelo propósito explícito de cada módulo, que reflete a intencionalidade dos docentes como princípio filosófico da ação, o que auxiliam professores na percepção de seu compromisso com o aluno.

Ramos (2001) estabelece dez premissas do desempenho. Delas pode-se inferir no ensino e aprendizagem de Metodologia de Pesquisa, que perante uma situação, o desempenho de diferentes indivíduos pode assumir parâmetros diferenciados, dependendo de sua competência em mobilizar conhecimentos, de ser o exercício em situações anteriores iguais e de empenho pessoal na atividade. Estar atento às diferenças individuais perante uma atividade é tarefa rotineira do fazer docente. Vale ressaltar que ter previamente como meta o enquadramento do desempenho do aluno em um modelo único pode bloquear a criatividade do educando e mesmo a do professor, mas alguns desempenhos precisam ser traçados com clareza até para facilitar a auto-avaliação.

Rogers (1972) já assinalava para a importância de o aluno aprender num contexto de liberdade e do professor não ser transmissor de informações, mas um facilitador da aprendizagem. $\mathrm{O}$ autor salienta quanto a liberdade para escolher os temas e as estratégias que possuam significado à construção do seu aprendizado.

A avaliação do desenvolvimento do aluno está implícita no ensino por competências; está associada a um perfil esperado para o profissional em situações concretas de 
sua prática. A avaliação do processo de ensino e aprendizagem no decorrer da formação do aluno é pautada pela elaboração coletiva de critérios considerados como princípios flexíveis norteadores do processo. Estes critérios visam direcionar a subjetividade do grupo de professores que acompanham os alunos. O importante, no processo de avaliação, como ressalta o documento SENAC (2003) e Luckesi (1998), é que o desempenho do aluno seja avaliado em diferentes momentos em razão do esperado para cada módulo.

O documento do SENAC citado por Hermández (1998) propõe as seguintes dimensões para a avaliação: diagnóstica inicial, formativa e recapitulativa.

Os autores descrevem a avaliação diagnóstica como recurso de entrada no processo de ensino-aprendizagem com a finalidade de identificar os conhecimentos anteriores do aluno e a partir deles planejar o processo de ensino-aprendizagem; a avaliação formativa, como instrumento para acompanhar o desenvolvimento e oferecer dados aos professores para adequações necessárias durante o processo; e a avaliação recapitulativa, como um processo de síntese de um tema ou curso; é o momento que se permite verificar-se os resultados esperados foram alcançados.

Luckesi (1998), em avaliação da aprendizagem escolar, salienta a importância da avaliação diagnóstica como proposição de encaminhamento. Afirma que a atual prática da avaliação escolar inviabiliza um processo democrático de ensino porque está mais preocupada em classificar para reprovar e, portanto, excluir.

A avaliação diagnóstica deve ser assumida como um instrumento de compreensão do estágio de aprendizagem em que se encontra o aluno, tendo em vista tomar decisões suficientes e satisfatórias para que possa avançar no processo de aprendizagem (LUCKESI, 1998, p.81).

A avaliação, segundo o autor, deve ser vista como um recurso auxiliar da aprendizagem e como tal deve estar direcionada para o crescimento do educando.

Partindo-se desse princípio devem-se propor as avaliações, elaborar os instrumentos, avaliar e utilizar os resultados obtidos. A avaliação compreendida como um 
instrumento de diagnóstico para o avanço permite perceber sua função em três dimensões referentes à compreensão: a) do sistema do ensino, porque permite verificar como está atingindo seus objetivos, b) do professor, porque este pode aquilatar a eficiência do seu trabalho e identificar os eventuais desvios e c) do aluno, porque permite a aquisição de consciência de seus limites e das necessidades de avanços e recuos.

Luckesi (1998) ressalta ainda que, para a avaliação cumprir todas essas funções, necessita ser conduzida com rigor técnico em todas as suas etapas desde o planejamento, a construção de instrumentos coerentes com uma concepção pedagógica democrática da educação até a coleta e análise dos dados realizados com rigor científico tendo por objetivo o crescimento do aluno e, finalmente, ela deve ser participativa, isto é, deve possibilitar que o professor e alunos, apoiados por instrumentos, possam chegar a um entendimento sobre a situação de aprendizagem e juntos discutir os passos seguintes da formação. $O$ autor conclui que, seguir as orientações desta perspectiva diagnóstica da avaliação, o professor estaria instrumentalizado para a superação dos desvios de uma educação antidemocrática.

O desempenho representa um recurso para o professor avaliar o desenvolvimento do aluno que não pode ser empregado como arma contra o mesmo e com objetivo de classificá-lo e de excluí-lo de possibilidades de trabalho e de aprimoramento. Assim o desempenho reflete o estágio concreto de habilidades e atitudes necessárias ao desenvolvimento de competências esperadas.

A avaliação é um meio para verificar e monitorar o desenvolvimento e a aprendizagem dos desempenhos necessários a uma dada situação.

\subsection{DOS INSTRUMENTOS DE AVALIAÇÃO}

A padronização de questões específicas para a avaliação da enfermagem poderia facilitar a comparação entre as instituições, o trabalho dos avaliadores, e inclusive a definição do panorama da educação superior de enfermagem, segundo padrões 
determinados. Entretanto, a especificidade colocada em um instrumento de avaliação não garante a qualidade desta avaliação.

Para garantir a qualidade da avaliação é preciso que seja confiável, justa, técnica e eticamente. O seu desenvolvimento deve se dar através de racionalidade técnica que assegure informações objetivas e confiáveis e resultados fidedignos, respeite os preceitos de equidade como liberdade de expressão, ausência de repressão e especialmente contribua com a justiça social e não para as desigualdades e exclusão (DIAS SOBRINHO, 2000).

A avaliação implica em submeter algo à apreciação, com o propósito de tomar decisões e fazer acompanhamento de uma dada realidade. "Há um carinho a percorrer e que implica a recuperação e explicitação dos referenciais usados e que devem orientar o processo de atribuição de significados que antecedem o processo de interpretação e tomada de decisão" (SORDI, 2006, p.59).

Segundo os avaliadores, "o instrumento e avaliação deve contemplar a visão global de saúde e avaliar a existência/oferta de experiências no processo educacional que permitam o exercício em áreas que possibilitem ações preventivas e multidisciplinares" (BRASIL, 2005, p.2).

Evidencia-se a necessidade de uma nova concepção de avaliação, na perspectiva formativa através de novos elementos e evidências. Nas diretrizes curriculares para os Cursos de Graduação em Enfermagem, o § único do art. $5^{\circ}$ coloca: "a formação do enfermeiro deve atender às necessidades sociais da saúde, com ênfase no SUS e assegurar a integralidade da atenção e a qualidade e humanização do atendimento" (BRASIL, 2001)

Para desenvolver uma formação capaz de gerar um enfermeiro com esse perfil é preciso utilizar a avaliação, que pode oferecer grande contribuição, pois "produz sentidos, consolida valores afirma interesses, provoca mudanças, transforma. Tem uma profunda dimensão pública" (DIAS SOBRINHO, 2002). 
Com certeza o papel do sistema de avaliação, e consequentemente do avaliador, é muito importante, mas a qualidade dos cursos não depende somente disso. A "avaliação é um dos instrumentos para a sustentação da qualidade do sistema de educação superior" (MEC, 2004, p. 9). O modelo de avaliação deve possibilitar o aumento da eficiência da instituição, quanto à utilização dos seus recursos, bem como de seu papel social. Sendo parte do debate, o destino dos egressos, assim como o público que atende diretamente, diferentemente da perspectiva neoliberal (OLIVEIRA; SOUSA, 1999).

A construção de critérios para a avaliação deve ser social e pública, levar em consideração a relatividade das diversas áreas de conhecimento, as prioridades institucionais e a finalidade a que se destina. É importante que as instituições atendam a critérios de excelência e cientificidade, mas também relevância social (DIAS SOBRINHO, 2000).

Segundo o art. $4^{\circ}$ da Lei $n^{\circ}$. 10.861, "a avaliação de cursos de graduação tem por objetivo identificar as condições de ensino oferecido aos estudantes, em especial os relativos ao perfil do corpo docente, às instalações físicas e à organização didática pedagógica" (BRASIL, 2004).

As diretrizes curriculares nacionais do Curso de Graduação em Enfermagem estabelecem como perfil do formando egresso/profissional (BRASIL, 2001):

a) "o enfermeiro com formação generalista", que segundo Rodrigues (2005, p.164), a formação generalista passa pela necessidade de superar o ensino fragmentado e voltado ao modelo curativo/hospitalar predominante na formação do enfermeiro. "Portanto, formar o enfermeiro generalista significa romper com esta concentração e direcionar a formação para outros espaços, como a Saúde Coletiva".

b) (o enfermeiro) deve ser "capaz de conhecer e intervir sobre problemas /situações de saúde-doença mais prevalentes no perfil epidemiológico nacional com ênfase na sua região de atuação, identificando as dimensões biopsicossociais dos seus determinantes". 
O enfermeiro deve analisar a situação de saúde da população a partir do enfoque epidemiológico, utiliza os conhecimentos, métodos e técnicas provenientes da epidemiologia para o planejamento dos sistemas de saúde, dos serviços e da programação das ações (ROUQUAYROL, 2003), função inerente da saúde pública.

c) (o enfermeiro) "capacitado a atuar com senso de responsabilidade social e compromisso com a cidadania, como promotor da saúde integral do ser humano".

Para falar de responsabilidade e cidadania no contexto da atuação da área

da saúde e do SUS, é preciso analisar a perspectiva do "binômio focalização e universalização", relacionado às questões da pobreza e da desigualdade social, assim como de classe social, de renda, de gênero, de raça e outros (COHN, 2005, p.385).

A focalização se dá no caso de problemas específicos, obedecer ao

aspecto utilitarista de qualquer política social, mas também pode significar reintegrar acesso efetivo a serviços essenciais, configura-se em direitos universais, "tornam os cidadãos formalmente iguais, quando na prática não são". Nesse olhar a focalização passa a ser uma estratégia de implantação da universalização da saúde (COHN, 2005, p.394-395). Ressalta-se que na última década, o debate da universalização e focalização perde espaço, as propostas para as políticas e programas de saúde destacam a atenção primária.

A atenção integral à saúde inclui a promoção, a proteção e a recuperação da saúde que engloba os diversos níveis de atenção componentes do sistema (SANTOS, 2004). A integração de todos os níveis de assistência, com um sistema com referência e contra- referência para atendimento em todos os níveis de atenção é de extrema importância, para garantir a integralidade do cuidar. Nesse contexto, a formação dos profissionais, comprometidos com essa lógica, contribui para um melhor desempenho do sistema.

Um componente importante para a avaliação é distinguir a avaliação da qualidade técnica institucional da avaliação qualitativa no sentido político. Através da análise 
organizacional pode-se evidenciar a eficiência gerencial, o funcionamento adequado e atendimento às diretrizes preconizadas, o que não significa que seja eficaz para desenvolver adequadamente o compromisso político histórico da instituição (DEMO, 1999).

Quanto ao perfil epidemiológico, permite descrever as condições de saúde da população, as doenças mais prevalentes e o acesso aos serviços em determinada região.

O campo de ação da epidemiologia, enquanto prática de Saúde Coletiva contribui para a redefinição das práticas, tendo como objeto as tendências demográficas, as desigualdades em saúde e os limites das políticas vigentes (ROUQUAYROL, 2003).

$\mathrm{Na}$ gestão do SUS a incorporação da perspectiva epidemiológica vincula-se ao processo de tomada de decisão para a formulação de projetos, de programas e da política de saúde, com ênfase na prevenção de riscos e agravos e na promoção da saúde (TEIXEIRA, 2003).

Os currículos regionais aparentemente poderiam ser uma solução para a diversidade do país, mas diminuiriam a flexibilidade posta nas diretrizes curriculares, ou seja, a possibilidade de cada curso desenvolver o seu PPP, voltado para sua vocação. Se, por um lado às diretrizes curriculares introduzem o conceito de flexibilidade, por outro, a preocupação coma organização curricular e com os conteúdos continua em evidência, caracteriza-se o controle e a regulação.

Algumas questões são consideradas norteadoras para efetuar a avaliação:

Como se instituem as relações para construir o conhecimento?

Quais os eixos que as diretrizes precisam concretizar?

Quem realmente utiliza a biblioteca e de que forma?

Como é a relação com os estágios? 
Como é a relação com os serviços?

Qual a participação dos serviços?

Qual a relação que os cursos têm com a realidade?

A construção coletiva de padrões de qualidade para a avaliação dos Cursos de Enfermagem representa um avanço, quanto à organização da categoria, mas na tentativa de criar "coesão social e possibilitar melhorar as escolas avalia-as segundo critérios "objetivos", os seus efeitos (poderão ser) opostos, os critérios poderão parecer objetivos, mas os resultados não o serão, dadas as diferenças" dos alunos, das regiões e das IES (APPLE, 2000, p.75).

\subsection{PROCESSO DE ENFERMAGEM SEGUNDO CALLISTA ROY}

Roy e Andrews (1991) colocam que, das atividades exercidas pela Enfermagem, a que se diferencia atribuindo ao enfermeiro o seu real caráter profissional, é denominada de processo de enfermagem.

Em se tratando de processo de enfermagem, temos atividades exclusivas de enfermagem. Estas sugerem haver a existência de um receptor, aqui então denominado "pessoa". Por esse ponto, ressalta-se a ênfase de Roy, de que cada pessoa tem a sua maneira própria de lidar as mudanças no seu estado de saúde, o que reflete pelo menos duas coisas: uma, que o processo de cuidar é, e tem que ser individualizado; e outro, que cada pessoa é ativa/participativa dentro desse processo.

O papel da Enfermagem é o de construir, junto com a pessoa, ferramentas que possibilitem a identificação do nível de adaptação e de capacidade para resistência frente às mudanças. Cabe também, a esses personagens, reconhecer dificuldades a fim de intervir o mais precocemente, objetivando a adaptação eficaz.

Essa participação da pessoa no processo de cuidar vai depender, no entanto, de alguns fatores, como idade, nível de consciência, entre outros. Ressalta-se que esses fatores interferem apenas na forma como se participa desse processo, porque o ser 
pessoa implica ter respostas (comportamentos) que contribuem ou não para o alcance da saúde (ROY; ANDREWS, 2001). Reconhece-se assim, que para Roy pensar em processo de enfermagem é também pensar na pessoa como um sistema adaptável.

O processo de enfermagem, à luz do modelo de adaptação de Roy, é constituído de seis etapas: avaliação de comportamento, avaliação de estímulos, diagnóstico de enfermagem, formulação de alvos, intervenção e avaliação. O processo aqui é visto como:

[...] uma abordagem de resolução de problemas para agrupar informações, identificar as necessidades de uma pessoa, selecionar e implementar abordagens para as ações de enfermagem e avaliar os resultados dos cuidados oferecidos (ROY; ANDREWS, 1991, p. 41).

Esse processo, então, segundo Roy se constitui das 6 fases acima citadas; e estas se relacionam entre si simultânea e contínua, o que não poderia ser diferente já que o processo está voltado para a pessoa (sujeito coletivo ou singular) como um ser holístico, integrado em suas partes. $O$ que faz as fases do processo serem simultâneas e contínuas é o fato de este se direcionar ao ser humano (pessoa) do qual se exigem constantes respostas ao meio em que vive, e de esse ser humano ser completamente integrado em suas partes.

Para Lopes; Araújo e Rodrigues (1999, p.98), o processo de enfermagem precisa ser constantemente avaliado, e isso se dá:

[...] na medida em que o avançar da profissão exige análise de seu desempenho diário, objetivando a melhoria dela. [...] além do trabalho processual, o uso de teorias que visam definir a enfermagem enquanto ciência, apresenta-se como necessário para compreender questões inerentes à pessoa, ao ambiente, e à meta da enfermagem. Questões essas essenciais para o desenvolvimento de um cuidado qualificado. 


\subsubsection{PRIMEIRA FASE: AVALIAÇÃO DO COMPORTAMENTO}

No primeiro passo do processo de enfermagem o enfermeiro age para ter a compreensão do estado de saúde da pessoa, visualizando o modo de lidar, ou adaptar-se ao meio em que a esta se encontra; é ir em busca do comportamento. Ao avaliar o comportamento, traça-se o perfil de saúde, em que se podem achar dois tipos de respostas: adaptação eficaz ou ineficaz. Uma promove integridade do ser, e outra age deteriorando essa integridade, ou pelo menos não contribui com ela.

Define-se então, comportamento como "ação ou reação sob circunstâncias específicas, podendo ser observável ou não" (ROY; ANDREWS, 2001, p. 431). Para realizar essa avaliação, o enfermeiro deve pensar em como avaliar essas respostas, utilizar então três recursos básicos: observação, mensuração e entrevista. A seguir ele vai comparar esses dados comportamentais levantados com padrões preestabelecidos a fim de atestar a manutenção da integridade, e ainda localizar os pontos fortes que a auxiliem no cuidar. Roy acrescenta que nesta fase, bem como em todo o processo, a comunicação é essencial. Mostra que, quando mais efetiva for a comunicação entre a pessoa e o enfermeiro, mas eficientes também serão as atividades de enfermagem. Diante disto, vê-se que uma comunicação não efetiva resulta em atividades de enfermagem questionáveis (ROY; ANDREWS, 1991).

Avaliar comportamento requer também avaliar estímulos, uma vez que todo comportamento se origina de um ou mais determinado estímulo, pode este ser interno ou externo. Os instrumentos para avaliação dos estímulos são os mesmos utilizados para avaliar o comportamento.

Estabelecer prioridades nas respostas comportamentais requer identificar junto à pessoa quais os estímulos focais, os contextuais e os residuais. É consenso para Roy e Andrews (1991), que alguns estímulos contextuais têm ação sobre o comportamento em qualquer modo de adaptação, sendo eles: etnia, estrutura familiar, idade, sexo, hereditariedade, fatores genéticos, conhecimento, utilização de drogas, álcool, cigarro, entre outros. 


\subsubsection{SEGUNDA FASE: AVALIAÇÃO DOS ESTÍMULOS}

Mencionar avaliação do comportamento da pessoa na abordagem de Roy e Andrews (1991) é também mencionar a avaliação dos estímulos, quer sejam internos ou externos. Para as referidas autoras, os estímulos internos correspondem ao eu da pessoa, enquanto os externos são aqueles oriundos do ambiente que a cerca.

Como constantemente estamos sujeitos a estímulos, permanentemente estamos emitindo respostas a eles. Essas respostas, contudo, acontecem através dos mecanismos de enfrentamento, sendo estes modos próprios inatos ou adquiridos de responder ao ambiente que nos cerca (LOPES; ARAÚJO; RODRIGUES, 1999).

A Enfermagem, nesta avaliação, terá como prioridade o comportamento que representa a maior ameaça ao usuário. A partir deste, juntamente com a pessoa, serão estabelecidos quais estímulos focais, contextuais e residuais vêm promover o padrão de comportamento observado, e reconhecido como adaptação ineficaz (ROY; ANDREWS, 2001).

É considerado um estímulo focal aquele que assume uma maior influência para o comportamento da pessoa. O enfermeiro estará em busca do que confrontou o usuário de imediato, e deve saber lidar de modo integrado uma vez que um comportamento pertencente a um modo pode resultar em um determinado estímulo focal, em outro modo. Por exemplo: o aumento de peso exagerado (comportamento ligado ao modo fisiológico) relacionado ao estímulo da ansiedade pode resultar em estímulo no modo de autoconceito. Tal exemplo mostra a complexidade de como se relacionam estímulos e comportamento nos quatro modos de adaptação (ROY; ANDREWS, 2001).

Os estímulos contextuais são aqueles que compõem a situação, sendo evidentes quanto a sua presença; mas não são responsáveis pela causa mais imediata do comportamento, apenas contribuem para o comportamento já provocado pelo estímulo focal. Nesse estímulo o enfermeiro precisará estar atento para o significado que a pessoa dá a determinada situação (ROY; ANDREWS, 2001). 
Por fim, os estímulos residuais são aqueles que influenciam o comportamento adotado pela pessoa. Eles produzem efeitos indeterminados que não podem ser avaliados. A avaliação desse tipo de estímulo pode ser de duas formas: uma, pela confirmação da pessoa de que ele a afeta; e, outra, pelo conhecimento teórico ou empírico do enfermeiro sobre a pessoa (ROY; ANDREWS, 2001). Esses estímulos têm como característica o fato de não poderem ser validados, e, quando o são, tornam-se estímulos focais ou contextuais.

Roy e Andrews (1991) trazem um exemplo envolvendo esses três estímulos para melhor compreensão deles. Segue o exemplo: uma pessoa está com dor nos dentes, pois perdeu a massa de uma de uma obturação muito profunda e, ao mastigar um pedaço de doce, sente um aumento dessa dor. Tal perda da obturação levou à exposição do nervo dentário e, assim, a dor. Tem-se, então, nessa situação, como estímulo focal, a perda da massa de obturação; o estímulo contextual está ligado ao uso do doce, que veio aumentar a dor já provocada pela perda da obturação; e, como estímulos residuais têm-se suposições sobre o tipo de pasta que é utilizada por essa pessoa, ou mesmo sobre os seus hábitos de higiene dentária.

\subsubsection{TERCEIRA FASE: DIAGNÓSTICO DE ENFERMAGEM}

Para Roy e Andrews (2001), diagnóstico de enfermagem é o resultado de um processo de avaliação sobre o estado de adaptação de uma pessoa. Ao se montar um diagnóstico de enfermagem, Gordon (1994 apud LOPES; ARAÚJO; RODRIGUES, 1999) afirma que se faz uso de componentes estruturais, sendo estes: o problema, os fatores etiológicos e as características definidoras (indicadores clínicos).

Para Roy, como viu até agora, o problema é a falha no mecanismo de enfrentamento, leva a pessoa a responder ao ambiente de modo ineficaz; os fatores etiológicos correspondem aos estímulos internos e externos; e as características definidoras correspondem ao comportamento adaptativo ineficaz da pessoa. Percebe-se assim, a grande proximidade entre o que seja problema e característica definidoras, de acordo com este modelo. 
Roy e Andrews (2001) oferecem três maneiras de se elaborar um diagnóstico de enfermagem: a) é realizada uma avaliação dos comportamentos em um único modo, leva-se uma afirmação (comportamento) que se liga a vários estímulos relevantes, ou seja, faz-se o enunciado de um comportamento observado, liga-se a ele os principais estímulos influenciadores; b) o agrupamento de vários comportamentos de um mesmo modo que são afetados por um único estímulo; c) um resumo de comportamentos que transpassam mais de um modo, afetados pelo mesmo estímulo, busca-se um padrão comportamental (LOPES; ARAÚJO; RODRIGUES, 1999; ROY; ANDREWS, 2001; GALBREATH, 2000).

No modo fisiológico de adaptação, Roy estabelece duas tipologias, um dos indicadores de adaptação eficaz e outra dos problemas adaptativos de recorrência comum. Essa última tipologia está em constante aperfeiçoamento através da utilização e desenvolvimento desse modelo, e se apresenta como uma classificação para o diagnóstico de enfermagem.

A experiência clínica do enfermeiro é que irá definir qual método vai ser utilizado para a formulação de um diagnóstico. Quanto maior for a sua experiência, maior será a sua capacidade para cruzar informações e fazer relação entre os modos adaptativos.

Galbreath (2000) relata que Roy e seus co-autores começaram a estabelecer uma relação entre os diagnósticos da NANDA e os modos de adaptação propostos por Roy, mas esse projeto não foi adiante, uma vez que a edição dessa obra antecedia a publicações mais recentes da Nanda. Mesmo assim, houve a publicação de uma listagem proposta por Roy, onde se aborda cada um dos modos adaptativos e seus respectivos diagnósticos encontrados na NANDA; no modo fisiológico, ainda houve o desdobramento de listar os diagnósticos por componente (necessidades básicas e processos complexos).

Lopes, Araújo e Rodrigues (1999) propõem uma relação entre os indicadores de adaptação positiva, os problemas comuns de adaptação associados a cada um dos modos separadamente, e os diagnósticos de enfermagem da NANDA. 


\subsubsection{QUARTA FASE: ESTABELECENDO METAS}

Roy (1984 apud ROY; ANDREWS, 2001) afirma que estabelecer metas é traçar afirmações claras sobre o que se espera do paciente ao ser assistido pela Enfermagem. É definir quais comportamentos são necessários à pessoa para que esta venha manter ou aumentar um comportamento adaptável, bem como modificar o que seja ineficaz. Tal afirmativa revela que o foco do enfermeiro, ao estabelecer metas, deve ser o comportamento, que nem sempre precisa ser ineficaz para ele poder intervir, mas é necessário também visualizar aqueles adaptáveis a fim de mantê-los ou mesmo aumentá-los.

Para estabelecer metas, o enfermeiro observa um comportamento, identifica quais mudanças são necessárias e determina um tempo para o alcance destas mudanças. (ROY; ANDREWS, 2001).

Quando determina um tempo para o alcance de seus objetivos, o enfermeiro também precisa, aliada à sua prática clínica, definir se seus objetivos deverão ser alcançados em curto ou longo prazo. E isso se dá através de uma boa análise do quadro clínico da pessoa, esses objetivos podem variar entre aqueles que são estabelecidos minuto/minuto, e aqueles de dia/dia. Normalmente as metas estabelecidas no modo fisiológico têm aprazamentos curtos, enquanto em outros modos, algumas podem chegar a meses.

Como ser participativo que é, interagir constantemente com o ambiente, a pessoa é personagem atuante no estabelecimento de metas, seja sugerir novos objetivos como também avaliar aqueles traçados pelo enfermeiro. Para Roy e Andrews (2001), envolver a pessoa nos objetivos de sua própria integridade levará a mesma a um maior desempenho por alcançá-los. E essa interação que também possibilita ao enfermeiro avaliar o raciocínio da pessoa e sua disposição para o restabelecimento.

Quando o enfermeiro estabelece metas, ele "ajuda a pessoa a lutar pelo seu potencial humano total" (ROY; ANDREWS, 2001, p.60). 


\subsubsection{QUINTA FASE: INTERVENÇÕES DE ENFERMAGEM}

Esta é uma fase de racionar como a pessoa irá alcançar as metas propostas e quais intervenções de enfermagem irão levar a pessoa ao alcance da adaptação.

Roy e Andrews (2001) tratam esta fase como uma questão de gerir estímulos, ou seja, o enfermeiro é responsável por fornecer, manter, aumentar, diminuir ou ausentar estímulos, já que esses são os responsáveis por ativarem os mecanismos de enfrentamento e assim desencadearem comportamentos.

Nesta fase, dois pontos são relevantes: o estímulo focal e o nível de adaptação da pessoa. Ambos têm uma ligação direta com a capacidade da pessoa para se adaptar de modo eficaz ou não.

Quando o enfermeiro altera estímulos, ele aumenta as chances da pessoa, através de seus mecanismos de enfrentamento, responder positivamente e emitir comportamentos positivos.

De modo didático, podemos subdividir esta fase em oito etapas: a) reflexão sobre os objetivos e como eles podem ser alcançados; b) seleção dos estímulos que precisam sofrer alterações; c) realização de uma lista com intervenções possíveis para aquele caso; d) escolha de quais intervenções tem maior probabilidade, se efetuadas, de alcançarem as metas estabelecidas; e) identificação das conseqüências e probabilidade de ocorrência de destas, em caso de implementação das intervenções selecionadas; f) avaliação do valor das consequências originadas pela implementação das intervenções, por fim, escolhidas; h) implementação das ações, cujas conseqüências de alta probabilidade alcancem as metas estabelecidas (valor desejável).

Um exemplo descrito por Roy e Andrews (2001) para melhor visualização prática desta fase, é: Uma pessoa internada num hospital tem como queixa não conseguir dormir bem a noite. Esse comportamento é consequência de pelo menos três 
estímulos: nível de barulho no posto de enfermagem (focal); cama desconfortável (contextual); fome (contextual).

O enfermeiro tem como meta que a pessoa irá conseguir dormir satisfatoriamente nos próximos turnos noturnos. Ele identifica os estímulos que precisam ser alterados e verifica o que seja focal e contextual. E assim lista algumas intervenções, chegando à seleção de três: alterar o nível de barulho no posto de enfermagem; alterar o conforto da cama; alterar a fome.

Por fim o enfermeiro determinará como irá ser executada a intervenção escolhida, que nesse caso, foi alterar o nível de barulho no posto de enfermagem.

Como prescrição de enfermagem para ser implementada nesse exemplo, temos: fechar a porta do quarto da pessoa a noite; reduzir o volume de conversas no posto de enfermagem a noite.

Obedecer a todo esse critério antes de intervir, leva as ações mais acuradas, que trarão um maior benefício e menor malefício àquele que está sendo assistido.

Como se pôde observar pelo exemplo acima, buscar alterar o estímulo focal, em muitos casos traz uma maior probabilidade de alcance das metas; este deve ser o foco do enfermeiro sempre que possível. E quando não se puder agir sobre estímulo focal, o enfermeiro deve atentar para os contextuais, no intuito de garantir uma melhor condição para adaptação positiva. Também, em alguns momentos, o enfermeiro terá como opção agir sobre estímulos focais e contextuais simultaneamente.

Nesta pesquisa, para a seleção das intervenções adota-se a classificação das Intervenções de Enfermagem (NIC), no intuito de se ter acesso a uma lista de intervenções e atividades de enfermagem, correlacionadas aos diagnósticos de enfermagem propostos pela NANDA.

A NIC proporciona uma listagem abrangente de intervenções e atividades adequadas a todas as especialidades de atuação da Enfermagem. Um outro benefício é ela 
proporcionar não apenas as intervenções, mas também o como realizá-las (atividades).

\subsubsection{SEXTA FASE: AVALIAÇÃO}

Avaliar, enquanto 6 $6^{\mathbf{a}}$ fase do processo de enfermagem, significa para Roy o momento em que o enfermeiro irá analisar a eficácia das intervenções implementadas. Para tanto, será necessário tomar base os três elementos que compuseram suas metas para uma determinada pessoa: comportamento, mudanças necessárias e tempo estabelecido (ROY; ANDREWS, 2001). E então deve-se levantar o questionamento: A pessoa atingiu os objetivos comportamentais traçados para ela? Quando a resposta é positiva se afirma que a intervenção de enfermagem foi eficaz.

O enfermeiro verifica-se a pessoa alcançou o comportamento adaptável que se objetivava, e se o fez dentro do tempo previsto. Este é um momento para uma nova avaliação do comportamento, sendo realizada após implementação das intervenções e respeito ao tempo estabelecido para que os mecanismos de enfrentamento gerassem respostas adaptativas.

Para avaliar o comportamento gerado, o enfermeiro utiliza as mesmas técnicas de quando foi levantar os dados inicialmente, sendo: observação sensível, mensuração e entrevista.

No momento da avaliação, o enfermeiro também pode constatar que seus objetivos não foram alcançados, e a partir deste momento, ele procederá à investigação sobre o que falhou. A falha para o não alcance das metas estabelecidas pode estar nas próprias metas, tidas como fora da realidade ou não aceitas/assimiladas pela pessoa, alvo da assistência; ou ainda pode estar numa avaliação incorreta, em que dados do comportamento podem ter sido levantados erroneamente (ROY; ANDREWS, 2001).

Uma resposta ineficaz leva o enfermeiro de volta ao primeiro passo do processo de enfermagem, e prosseguir passo a passo observar o(s) comportamento(s) ineficaz(es) para então compreender sua atual situação (ROY; ANDREWS, 2001). 
Para uma melhor compreensão do processo de enfermagem é coerente apresentá-lo, passo a passo, em suas fases separadamente. Contudo a vivência clínica mostra um processo cujas fases se entrelaçam e que ocorre de forma contínua. Nem sempre se avalia um comportamento dissociado de seu estímulo, ambos podem ser constatados simultaneamente. E assim ocorre o processo de enfermagem, em que a única regra constante é a pessoa, alvo da assistência de enfermagem.

\section{METODOLOGIA}

Para realização deste estudo, optou-se pela pesquisa bibliográfica em livros, dissertações de mestrados e artigos científicos obtidos em revistas e periódicos tais como, Lilacs, Bireme, Medline, Scielo, dentre outros.

Segundo Gil (1991, p.48), a pesquisa bibliográfica é aquela "[...] desenvolvida a partir de material já elaborado, constituído principalmente de livros e artigos científicos". Mas a pesquisa bibliográfica também inclui outras modalidades de publicação, tais como artigos de revistas e jornais direcionados ao público em geral.

A pesquisa bibliográfica pode conduzir a novas visões sobre um determinado problema.

Segundo Parra Filho e Santos (2002, p.37), "[...] qualquer que seja o campo a ser pesquisado, sempre será necessária uma pesquisa bibliográfica, para se ter um conhecimento prévio do estágio em que se encontra o assunto".

Pesquisaram-se as bibliografias e as fontes. As fontes referem-se a textos originais relacionados a um determinado assunto. A bibliografia diz respeito aos esclarecimentos referentes às fontes; é toda a literatura originária de determinada fonte ou de assunto.

A leitura exploratória e interpretativa favoreceu a construção dos argumentos por progressão ou por oposição. 


\section{CONCLUSÃO}

Pode-se afirmar que o processo de enfermagem, como atribuição do enfermeiro, é essencial para sua assistência cotidiana, tendo em vista que este leva a Enfermagem a se desenvolver como ciência, busca fundamentação para sua prática através de um raciocínio crítico, lógico e científico. E este processo se guiará por teorias ou modelos conceituais de enfermagem, bem como por conhecimentos científicos e experiências pessoais.

As teorias de enfermagem vêm contribuindo com a construção do conhecimento de enfermagem e, consequentemente, com a assistência de enfermagem ao serem utilizadas como um guia que melhora a prática, o condutor na observação dos fenômenos, na intervenção, e nos resultados esperados. Uma sistematização apoiada em modelos teóricos vem proporcionar meios para organizar a investigação dos clientes, para proceder com análise e interpretação dos dados, para traçar diagnósticos, planejar, implementar e avaliar esse processo de cuidar; e isto torna o processo de cuidar em um resultado daquilo que se conhece, e se pesquisa. Assim o processo de enfermagem é o elo que une a teoria à prática.

A sistematização através do processo de enfermagem é legalmente um dever da Enfermagem, tendo o seu amparo na Resolução 272/2000 do Conselho Federal de Enfermagem, que dispõe sobre a sistematização da assistência de enfermagem nas instituições de saúde brasileira. E, para além do dever, o processo de enfermagem proporciona uma melhora significativa da assistência prestada, contribuindo ainda para o embasamento da profissão como ciência.

Como método de prestação de cuidados, o processo de enfermagem é aplicável em qualquer ambiente, dependendo apenas da disposição para planejá-lo e executá-lo. Alguns fatores, no entanto, facilitam essa prática, sendo um deles a construção de instrumentos que contemplem este exercício, baseados no perfil do atendimento a quem se destina. 


\section{REFERÊNCIAS}

ALFARO-LEFEVRE RA. Aplicação do processo de enfermagem - promoção do cuidado colaborativo. São Paulo: Artmed, 2005.

ANDRE MEDA; PASSOS LF. Avaliação escolar: desafio e perspectivas. In: CASTRO AD; CARVALHO AMP. (Org.) Ensinar a ensinar. São Paulo: Pioneira, 2001. p.1771195.

APPLE MW. A política do conhecimento oficial: faz sentido a idéia de um currículo nacional. In: MOREIRA, A. F; SILVA, T.T. (Orgs.). Currículo, cultura e sociedade. Trad. Por Maria Aparecida Batista. 4 ed. São Paulo: Cortez, 2000. P. 59-91. Cap.3.

ARANTES CIS. Saúde coletiva: os (dez) caminhos da construção do ensino de enfermagem [tese]. São Paulo: Escola de Enfermagem, Universidade de São Paulo; 1999.

ASSOCIAÇÃO BRASILEIRA DE ENFERMAGEM (ABEn). Proposta de novo currículo mínimo para o curso superior de enfermagem: a formação do enfermeiro. Brasília; 1991.

BAGNATO MHS. Licenciatura em enfermagem: para quê? [tese]. Campinas: Faculdade de Educação, Universidade Estadual de Campinas; 1994.

BRASIL. Ministério da Educação. Parecer CNE/CES 1133/2001. Estabelece as diretrizes nacionais dos cursos de graduação em enfermagem, medicina e nutrição [legislação na Internet] Brasília; 2001. Disponível em: http://www.mec.gov.br/index.php?

BRASIL. Ministério da Saúde. Conselho Nacional de Saúde. Princípios e diretrizes para NOB/RH-SUS. 2 ed. Brasília; 2003. Disponível em: <http://bvsms.saude.gov.br/bvs/publicacacoes/principios_diretrizes_NOB_2003.pdf> 
BRASIL. Ministério da Saúde. Conselho Nacional de Saúde. Relatório final da 12ª Conferência Nacional de Saúde; 2003 dez. 7-11; Brasília. Brasília 2004. Disponível em: <HTTP://conselho.saude.gov.br/biblioteca/relatorios/relatorio_12.pdf>

BRASIL. Ministério da Saúde. Programa Nacional de Reorientação da Formação Profissional em Saúde - Pró -Saúde. Brasília; 2005. Disponível em www.bvsms.saude.gov.br.

BRASIL. Ministério da Saúde. Conselho Nacional de Saúde. 13ª Conferência Nacional de Saúde. Inform Eletrônico CNS. 2007 fev. Disponível em: http:conselho.saude.gov.br/biblioteca/Informativo13conferencia.pdf>

BUDÓ MLD, SAUPE R. Conhecimentos populares e educação em saúde na formação de enfermeiros. Rev Bras Enferm. 2004; 57(2):165-9.

BURNIER, S. Pedagogia das competências: conteúdos e métodos. 2003. Disponível em: www.senac.br/informativo/BTS/273/boltec273e.htm

CAMPOS GWS. Paidéia e modelo de atenção: um ensaio sobre a reformulação do modo de produzir saúde. Olho Mágico. 2003; 10(2):7-14.

CAMPOS RM. Satisfação da equipe de enfermagem do serviço pré-hospitalar móvel às urgências (SAMU) no ambiente de trabalho. Natal, 2005. 128 p. Dissertação (mestrado) - Universidade Federal de Rio Grande do Norte. Centro de Ciências da Saúde. Programa de Pós-graduação Ciências da Saúde. Natal, 2005.

CECCIM RB, FEUERWERKER LCM. O quadrilátero da formação para a área da saúde: ensino, gestão, atenção e controle social. PHYSIS Rev Saúde Coletiva. 2004; 14(1):41 - 65 .

CONSELHO FEDERAL DE ENFERMAGEM. Resolução no 290/2004. Fixa as especialidades de enfermagem. Rio de Janeiro, 2004. 
CONSELHO FEDERAL DE ENFERMAGEM. Resolução no 300/2005. Dispõe sobre a atuação do profissional de enfermagem no atendimento Pré-hospitalar e Inter hospitalar. Rio de Janeiro, 2005.

DEMO, P. Avaliação qualitativa. 6ª Ed. Campinas: Autores Associados, 1999.

DIAS SOBRINHO, J. Avaliação da educação superior. Petrópolis: Vozes, 2000.

DIAS SOBRINHO, J. Quase-mercado, quase-educação, quase-qualidade: tendências e tensões na educação superior. Avaliação. Campinas/SP, v.7 n.1, p.9-33, mar. 2002.

DILLY CML, JESUS MCP. Processo educativo em enfermagem: das concepções pedagógicas à prática profissional. São Paulo: Robe; 1995.

FEUERWERKER LCM. Além do discurso de mudança na educação médica: processos e resultados. São Paulo: Hucitec; 2002.

GALBREATH JG. Sister Callista Roy. In: GEORGE JB. Teorias de Enfermagem: dos fundamentos a prática. 4를 Ed. Porto Alegre: Artes médicas, 2000.

GALLEGUILLOS TGB, OLIVEIRA MAC. A institucionalização e o desenvolvimento da enfermagem no Brasil frente às políticas de saúde. Rev Bras Enferm. 2001; 54(3):466-74 .

GARCIA TR; NÓBREGA MML. Sistematização da assistência de enfermagem: reflexões sobre o processo. In: 52 CONGRESSO BRASILEIRO DE ENFERMAGEM, 2000, Recife/Olinda-PE. Anais... Enfermagem 2000: Crescendo na Diversidade. Recife-PE: ABEn-PE, 2002.v. 1, p. 231-243.

GERMANO R. Educação e ideologia da enfermagem no Brasil. $2^{\mathrm{a}}$ Ed. São Paulo: Cortez; 1983.

GIL AC. Como elaborar projetos de pesquisa. Atlas: São Paulo, 1991. 
KOBAYASCHI RM, LEITE MMJ. Formação de competências administrativas do técnico de enfermagem. Rev Lat Am Enferm. 2004; 12(2):221-7.

LOPES MVO; ARAÚJO TL; RODRIGUES DP. A relação entre os modos adaptativos de ROY e a taxonomia de diagnósticos de enfermagem da NANDA. Rev Latino Am Enfermagem. Out. 1999, vol.7, n.4, p.97-104.

LUCKESI C. et al. Fazer universidade: uma proposta metodológica. São Paulo: Cortez, 1998.

MEYER DE. Espaços de sombra e luz: reflexões em torno da dimensão educativa da enfermagem. In: Meyer DE, Waldow VR, Lopes mjm (orgs). Marcas da diversidade: saberes e fazeres da enfermagem contemporânea. Porto Alegre: Artes Médicas; 1998. P. 27- 42.

MONTICELLI M. As ações educativas em enfermagem: do senso comum ao bom senso. Texto Contexto Enferm. 1994; 3(2):7-16.

MORAES MJB. O ensino de enfermagem em saúde coletiva: redescobrindo caminhos para novas práticas assistenciais [dissertação]. São Paulo: Escola de Enfermagem, Universidade de São Paulo; 2003.

OLIVEIRA MAC. Da intenção ao gesto: a dialética da formação de enfermagem em saúde coletiva [tese livre-docência]. São Paulo; Escola de Enfermagem, Universidade de São Paulo; 2004.

OLIVEIRA RP; SOUSA SMZL. A avaliação de curso: uma dimensão da avaliação na universidade. Revista Adusp, São Paulo, n. 18, out. 1999. p. 30-35.

PARRA FILHO D, SANTOS JA. Metodologia científica. 5aㅡ. Ed. São Paulo: Futura, 2002.

PERRENOUD P. Construir as competências desde a escola. Porto Alegre: Artes Médicas Sul, 1999. 
PERRENOUD $\mathrm{P}$. Diferenciação e práticas pedagógicas favoráveis à transferência de conhecimentos. Porto Alegre: Artes Médicas Sul, 2000.

RAMOS MN. Qualificação, competências e certificação: visão educacional. Formação, Brasília, v. 1, n. 2, p. 5-15, maio 2001.

RIGOLI F, ROCHA CFR, FOSTER AA. Desafios críticos dos recursos humanos em saúde: uma visão regional. Rev Lat Am Enferm. 2006; 14(1):7-16.

ROGERS CR. Liberdade para aprender. $2^{\mathrm{a}}$ Ed. Belo Horizonte: Inter livros, 1972.

RODRIGUES RM. Diretrizes curriculares para a graduação em enfermagem no Brasil: contexto, conteúdo e possibilidades para a formação. 2005. 249p. Tese (Doutorado) - Faculdade de Educação, Universidade Estadual de Campinas, Campinas, 2005.

ROSSI LA; CASAGRANDE LDR. Processo de enfermagem: a ideologia da rotina e a utopia do cuidado individualizado. In: CIANCIARULO TI; GUALDA DMR; MELLEIRO MM; ANABUKI MH. Sistema de assistência de enfermagem: evolução e tendências. São Paulo:Ícone, 2001.

SANTOS NR. A efetivação do SUS - travessia tão difícil como desafiante. 2004 (Mimeografado).

ROY SC; ANDREWS HA. The Roy adaptation model; the definitive statement. Norwalk, Connecticut: Appleton e Lange, 1991.

ROY SC; ANDREWS HA. Teoria da Enfermagem: o modelo de adaptação de Roy. Lisboa: Instituto Piaget, 2001.

SAUPE R. Educação em enfermagem: da realidade construída à possibilidade em construção. Florianópolis: Ed. UFSC; 1998. Ação e reflexão na formação do enfermeiro através dos tempos; p. 29-73. 
SERVIÇO NACIONAL DE APRENDIZAGEM COMERCIAL. 3. A organização curricular no modelo baseado em competências. 2003. Disponível em: www.senac.br/conheca/ referenciais/ref3.htm

SILVA GB. Enfermagem profissional: análise crítica. 2ª Ed. São Paulo: Cortez; 1986.

SORDI MRL. Avaliando o ensino de Enfermagem no contexto do SINAES: potencialidades e fragilidades. In: TEIXEIRA E; VALE EGV; FERNANDES JD; SORDI MRLD. $O$ ensino de graduação em Enfermagem no Brasil: o ontem, o hoje e o amanhã. Brasília: INEP, 2006.

TEIXEIRA CF. Epidemiologia e planejamento em saúde. In: ROUQUAYROL MZ; ALMEIDA FILHO N. Epidemiologia e saúde. 6ª ed. Rio de Janeiro: MEDSI, 2003.

Universidade estadual de londrina. Colegiado do Curso de Enfermagem. Currículo integrado de Enfermagem: ano 2000. Londrina, 1999.

VALLA VV. [Entrevista]. Trab Educ Saúde. 2005; 3(1):227-38.

VASCONCELOS EM. Redefinindo as práticas de saúde a partir de experiências de Educação Popular nos Serviços de Saúde. Interface Comum Saúde Educ. 2001; 5(8): $121-6$.

Enviado: Janeiro, 2020.

Aprovado: Junho, 2020. 